Article

\title{
Engendering Creative City Image by Using Information Communication Technology in Developing Countries
}

\author{
Dillip Kumar Das \\ Central University of Technology, Free State, 9301 Bloemfontein, South Africa; E-Mail: ddas@cut.ac.za
}

Submitted: 14 June 2016 | Accepted: 9 August 2016 | Published: 8 September 2016

\begin{abstract}
Creativity has been a major key word in the city planning and urban marketing policies all over the world. Arguably, it ensures an image that can ensue marketable branding of a city. Thus, a creative city has major socio-economic implications. However, the question remains how a creative environment in a city can be engendered and an attractive image be built. In the contemporary age, Information Communication Technology (ICT) apparently has increasingly been influencing every sphere of the city functions, and it is hypothesized that it will assist in building a creative image of a city. Therefore, the objectives of the paper are (1) to map the theoretical insights on the concepts of creativity, city image building and branding; and (2) to explore the influence of ICT on developing the image of a creative city. The investigation was conducted by using both qualitative and quantitative research methods. A stimulating mix of literature review and case study analyses were done to develop the concept of a creative city and image building. Besides, using a survey research method and by considering two cities (Bloemfontein in South Africa and Bhubaneswar in India) two case studies were performed to examine how ICT can engender a creative image of a city in developing countries. Findings suggest that although urban creativity is not a revolutionary approach towards urban policies, and there are criticisms against such a concept; distinct images of cities are enforced by (a) economic variables, such as, business environment, entrepreneurship and innovation, availability of knowledge workers and ICT activities; (b) socio-cultural variables, such as, art, culture, receptive attitude, safety and tolerance; and (c) environmental variables, such as, cleanliness, greenery, quality public spaces and tourism. It is also revealed that ICT can play a catalytic role in creative image building as it contributes extensively in the form of enabling a better business environment, bringing social cohesion and multicultural tolerance, promoting tourism and engendering a clean environment. However, the image of every city could be unique depending on the attributes being focused on and reinforced in the development of a city.
\end{abstract}

\section{Keywords}

creative image; city branding; entrepreneurship; environment; ICT; socio-cultural

\section{Issue}

This article is part of the issue "Sustainable Planning and Technologies", edited by Hatem Ibrahim (Qatar University, Qatar), Ahmed Khan (Université Libre de Bruxelles, Belgium), Steffen Lehmann (University of Portsmouth, UK), Dellé Odeleye (Anglia Ruskin University, UK) and Atiq Zaman (Curtin University, Australia).

(C) 2016 by the author; licensee Cogitatio (Lisbon, Portugal). This article is licensed under a Creative Commons Attribution 4.0 International License (CC BY).

\section{Introduction}

Of late a unique phenomenon in the city development process is apparently seen across the world. With the inculcation of globalisation and market economy, competitiveness has been engendered among the cities in the globalised world. Cities are found to often compete directly with their peers at both regional and global level
(Jiang \& Shen, 2010). While certain global cities such as New York, London, and Tokyo compete with each other and their international competitors (Sassen, 1991), cities of Europe become more concerned and alert about the opportunities and competitions arising out of increased European integration. Similarly, cities in the Asian continent such as Beijing, Hong Kong, Singapore and more recently Dubai are seeking to establish themselves at 
the global level (Jessop \& Sum, 2000; Lever, 1993; Shen, 2008; Xu \& Yeh, 2005). Furthermore, at a regional level, certain rising cities like Guangzhou and Shanghai in mainland China, and Delhi, Mumbai, Ahmadabad, Pune, Bengaluru, etc., in India, face competition from each other (Jessop \& Sum, 2000; Jiang \& Shen, 2010; Shen, 2007; Xu $\&$ Yeh, 2005). The competition is basically with respect to (but not limited to) attracting foreign direct investment (FDI), national projects, creation of an economic image, attracting tourists, and more recently to becoming smart (Gold \& Ward, 1994; Vanolo, 2008). Consequently, many national and local governments have come under intensifying pressure and in turn vigorously responded by incorporating a variety of policies aimed at creating the image of cities, building marketable brands and enhancing their competitiveness (Jiang \& Shen, 2010; Shen, 2004, 2007). Even the relatively smaller and provincial cities have entered in this race of image building-particularly in developing countries like India and South Africa. As a result, image building, branding, preferential policies, competition and competitiveness have become important topics of study in the urban planning and development study.

However, many studies have equated urban competitiveness with economic success such as economic outputs, income and employment generation (Jiang \& Shen, 2010). Accordingly, efforts were made to create an image and brand of the cities, keeping economic success in view. Besides, spatial development engendering aesthetic appeal and enhancing tourist attractions; social cohesion through encouraging cosmopolitanism; and creativity by inspiring research, innovation, knowledge creation and enhancing art and culture, were loosely integrated in the development process (Florida, 2002, 2003, 2005; Jiang \& Shen, 2010; Sassen, 1991, 1999; Vanolo, 2008). However, the scenarios changed with the advent and introduction of Information Communication Technology (ICT). Over the last two decades ICT has invaded almost all spheres of life-particularly in the urban areas. Not only has it blurred the time distance relationship and changed the way almost all the urban activities-including economic and social activities used to be accomplished, but it has also influenced the physical and spatial environment of the cities. Moreover, art, culture, music, sports, research and innovation, to name a few, are also largely influenced by ICT. It is also an accepted fact that ICT will be strengthened further, and more and more urban activities are expected to be performed with the aid of ICT (Van der Vyver \& Marais, 2015; Das \& Emuze, 2014; Giffinger et al., 2007; Ponelis \& Holmner, 2015). As a result, ICT will become pivotal in the overall city development process and realization of creative images of the cities. Besides, as suggested by Batty (2012), the building of cities is a highly complex process and is open to embrace many ideas, elements and technologies. Technology, particularly ICT, has been observed to be-and also testifies in some cases (e.g., Dubai, Osaka, New York, and Singapore) as the symbol of development, power and creativity. Incidentally, extensive research has been done at individual and aggregate level with regards to the domain of ICT as a technology, the use of ICT, and the influence of ICT on socio-economic, recreational and entertainment, tourism and transportation activities. The majority of these studies have been confined to larger cities and to the developed world, although sporadic studies have been conducted by considering lesser cities in the developing or underdeveloped world. Nevertheless, not much investigation has been seen related to the influence of ICT on the development of a creative city imageparticularly in smaller and medium cities in the developing world. Thus, understanding of the influence of ICT on developing a creative city image-particularly in lesser known cities in the developing world, is warranted, as such cities also keep similar aspirations. Therefore, this study first mapped the theoretical insights on the concepts of creative city image building and then explored the influence of ICT on developing the image of a creative city. The contributions of this paper are that (1) based on literature, it developed a discourse on creative city image and identified a set of attributes that influence engendering a creative city image, and that (2) it ascertained that ICT is a major influential factor in creating a creative city image-even in relatively not so well known and smaller cities and-thus need to be an important criterion to be considered while developing policies for image building of such cities.

The following sections of the paper elicit the approach of the investigation, mapping of the theoretical insights of an image of a creative city, comprehending the influence of ICT on the creative city image building, discussions and concluding remarks.

\section{Approach of the Study}

To realize the objectives, both qualitative and quantitative research methods were used. The concept of creative city image and branding was developed through critical review of literature and case study analyses. In addition, a survey research method was used to collect data, followed by quantitative statistical analyses. For this purpose two cities-Bhubaneswar in India and Bloemfontein in South Africa-were taken as case studies.

Bhubaneswar located in the eastern region of India, is one of the fastest growing medium sized cities of the country. An unprecedented demographic, spatial, economic, commercial and industrial growth has been experienced in the city during the last decade and a half. More importantly, the city has gradually transformed from being a small provincial administrative capital to being a hub of higher education and ICT based industrial activities. A significant number of institutions engaged in knowledge creation and industries engaged in ICT oriented activities and knowledge economy is located in the city. Consequently, the city has become one of the major urban centers in the eastern region of the country, and the Government of India has recently declared 
it to be developed as one of the smart cities of the country. Bloemfontein is the capital of Free State province and one of the three national capitals-judicial capitalof South Africa. In 2012, the erstwhile Mangaung (the native name of the Bloemfontein city) municipality has become the Mangaung metro municipality with the incorporation of the two towns such as Thaba 'Nchu and Boshabelo as well as other smaller settlements in and around Bloemfontein. Consequently, Bloemfontein has become the largest constituent of the newly formed metro municipality. The city encompasses two large universities and a number of well-known schools and health facilities. It is the hub for knowledge oriented activities and health facilities of the central region of the country. Besides, a significant amount of ICT oriented activities are being incorporated in the city. Moreover, the city development authority-the metro municipalityhas envisaged to transform the city into a vibrant and sustainable world class city. Although, these two cities do not have any kind of noteworthy image and are not well known internationally, they have become competitive at the national level in their respective countries. Furthermore, their city development authorities have envisaged transforming these two cities to world class cities in a foreseeable period (IDP, 2015; City Development plan, Bhubaneswar, 2006). Therefore, these two cities become ideal candidates for this investigation in the wake of similar aspirations of a number of cities in developing countries.

To collect data, a survey was conducted among the stakeholders and common people by using pre-tested questionnaires and by applying a random sampling process. The stakeholders constitute academicians, urban planning professionals, engineers, architects, city development officials, students, business men, merchants, personnel from ICT industry, people from advertising and image building industry, politicians, and municipal councillors. Besides, common people aware of the city development and image building process were selected for the survey. The selection of respondents was done by personal contacts after initial scrutiny of their awareness of and engagement in the city development and image building process. During initial scrutiny, care was taken to observe the personal profiles and professional activities of respondents and their engagements with regards to city development, creativity and creative city image and to avoid personal bias, prejudices and affiliation with the investigator. The searching of profiles was done by using online search engines like Google, contacting relevant organisations and institutions, and examining various promotional materials, and advertisements available at the study area level. Then, from the search and subsequent scrutiny, a list of 550 people (prospective respondents)which includes both professionals and common citizens who are either aware of or engaged in the city development process, creative activities and the creative image of cities-was drawn by using a random sampling process. Once the list of prospective respondents was drawn, they were contacted via telephone, e-mail (if available) or personal contacts visiting them, to determine their suitability for the survey and to invite them to participate in the survey if found suitable. While selecting respondents, care was also taken not to discriminate against or exclude any person based on his/her race, gender, religion, social and economic status, occupation and similar attributes. Of the total contacts made, about 378 people $(68.72 \%)$ responded positively and gave their consent to participate of which 38 people later withdrew. Eventually, the survey was conducted among the willing participants (with total sample size of 340-210 from Bhubaneswar and 130 from Bloemfontein) by using a pretested questionnaire. Table 1 presents the various demographic and professional attributes of the respondents. Of the total number of respondents about one third are professionals and the remaining two thirds are common citizens. The gender, age and professions of respondents are also proportionately distributed, thus avoiding any bias in the sampling process towards a particular segment of people in both cities.

The various variables to be investigated were compiled from the established literature and scrutinised for their relevancy both to the investigation and the study areas. The variables investigated include economic variables, such as business environment, entrepreneurship and innovation; availability of knowledge based activities as well as knowledge workers; socio-cultural variables, such as architecture, heritage, culture, receptive attitude, social cohesion, safety and tolerance; and environmental variables, such as cleanliness, greenery and tourism, quality of public spaces and spatial hotspots (Batty, 2012; Florida, 2005; Gertler, 2004; Gold \& Ward, 1994; Giffinger et al., 2007; Kavaratzis \& Ashworth, 2005; Lalli, 1992; Landry, 2006; Landry \& Bianchini, 1995; Moser, 2010; Peck, 2005; Sassen, 1999; Shields, 1991; Vanolo, 2008). As mentioned earlier, ICT has also gained significance in every sphere of life including social, economic, transportation, education, health, tourism, recreation and entertainment activities to name a few. Availability of ICT facilities and services-particularly in urban areas-has become an essential requirement for smooth functioning of daily urban life. Internet connectivity such as broadband, wi-fi (wireless internet connectivity), internet hotspots, and associated digital technology related equipment and accessories such as computers, laptops, smart mobile phones, tablet computers, GPS instruments, smart watches, and similar gadgets have become an integral part of human life through which the majority of socio-economic and related urban functions are being performed by people. The presence of such ICT related facilities and equipment and their service quality also develop an image of a place. The availability of technological variables such as ICT facilities, penetration of ICT in urban activities, quality of ICT facilities, and level of use of ICT facilities in urban areas as well as how ICT influences the economic, socio-cultural and environmental variables in building a creative image of a city (Van der 
Table 1. Profile of respondents.

\begin{tabular}{|c|c|c|c|c|c|c|c|c|}
\hline \multicolumn{3}{|l|}{ Profession } & \multicolumn{3}{|c|}{ Gender } & \multicolumn{3}{|c|}{ Age } \\
\hline \multirow[b]{2}{*}{ Category } & \multicolumn{2}{|c|}{ Share } & \multirow[b]{2}{*}{ Category } & \multicolumn{2}{|c|}{ Share } & \multirow[b]{2}{*}{ Age group } & \multicolumn{2}{|c|}{ Share } \\
\hline & Bhubaneswar & Bloemfontein & & Bhubaneswar & Bloemfontein & & Bhubaneswar & Bloemfontein \\
\hline Academicians & $12(5.7)$ & $6(4.6)$ & Male & $134(63.8)$ & $81(62.3)$ & $15-24$ & $34(16.2)$ & $18(13.8)$ \\
\hline Urban planning professionals & $5(2.4)$ & $3(2.3)$ & Female & $76(36.2)$ & $49(37.7)$ & $25-35$ & $71(33.8)$ & $51(39.2)$ \\
\hline Engineers & $4(1.9)$ & $4(3.1)$ & Total & $210(100.0)$ & $130(100.0)$ & $36-50$ & $62(29.5)$ & $40(30.8)$ \\
\hline Architects & $5(2.4)$ & $2(1.5)$ & & & & $51-60$ & $38(18.1)$ & $16(12.3)$ \\
\hline City development officials & $6(2.9)$ & $4(3.1)$ & & & & $>60$ & $9(4.3)$ & $5(3.8)$ \\
\hline Students & $16(7.6)$ & $12(9.2)$ & & & & Total & $210(100.0)$ & $130(100.0)$ \\
\hline Business men, and merchants & $5(2.4)$ & $4(3.1)$ & & & & & & \\
\hline Personnel from ICT industry & $6(2.9)$ & $4(3.1)$ & & & & & & \\
\hline People from advertising and image building industry & $3(1.4)$ & $2(1.5)$ & & & & & & \\
\hline Politician, municipal councillors & $7(3.3)$ & $3(2.3)$ & & & & & & \\
\hline Total professionals & $70(33.3)$ & $44(33.8)$ & & & & & & \\
\hline Common citizens & $140(66.7)$ & $86(66.2)$ & & & & & & \\
\hline Total & $210(100.0)$ & $130(100.0)$ & & & & & & \\
\hline
\end{tabular}

Note: The numbers in brackets show values in percentage. 
Vyver \& Marais, 2015; Das \& Emuze, 2014; Giffinger et al., 2007; Ponelis \& Holmner, 2015; Yang \& Meng, 2001) were investigated. The data collected was quantitatively analyzed by use of descriptive statistics, development of a perception index (PI) (Das \& Emuze, 2014; Lambsdorff, 2006; Nardo et al., 2005; Saltelli, 2007), and significance tests. In addition, qualitative discussions with some stakeholders such as urban planning professionals, decision makers, academicians and people engaged in image building and branding were done through non structured interviews to corroborate the findings of the study and understand the threshold of the indices.

The perception index $(\mathrm{PI})$ was measured by using the model given in Equation 1:

$$
\mathrm{PI}=\frac{\sum \mathrm{W}_{i} \times \mathrm{N}_{i}}{\sum \mathrm{N}_{i}}
$$

Where $W_{i}$ is the perception index values assigned by the respondents for each variable in a scale of 0 to 1 . $\mathrm{N}_{i}$ is the number of respondents assigning a particular index value.

\section{Theoretical Insights to Creative City Image}

According to Batty (2012) and Miller and Page (2007), the science of building cities is highly complex; yet sufficiently open to embrace many different approaches and ideas. It has been recognised that cities accept innovation-rather they are the crucibles of innovation and engender surprises (Batty, 2012). The functions of the cities in space and time are based on a multitude of processes of spatial choice in which individuals and groups in the population locate with respect to one another and their wider activities in the form of land use types. These activities are apparently controlled by trade-offs between economic and non-economic activities. Consequently these trade-offs lead to patterns of activity that reflect different spatial, socio-economic and environmental images and also develop spatial patterns (Batty, 1971, 2012; Shields, 1991; Vanolo, 2008). The image creation attributes not only include the visual images, but also many other elements such as aspects relating to the symbols embodied in the material components of the city (roads, monuments, and buildings). In addition, many immaterial components such as the habits, routines, institutions and organizations regulating the life of the inhabitants are part of this image. Furthermore, discourses about the city, typecasting of the attitudes of the inhabitants, and descriptions in tourist guides, movies, slogans, and local marketing campaigns also enforce the creation of a city's image. These spatial patterns, socio-economic and environmental attributes and metaphorical attributes create different images of the cities by which they are identified in the longer run. Moreover, the construction of images of cities is generally analysed from perspectives such as (1) the internal image: perceived and reproduced by the local actors of the city, those who identify with the geographi- cal identity of that particular place (Lalli, 1992); and (2) the external image: the perception and representation of the city by (and for) people and organizations more or less extraneous to local life and symbols (Entrikin, 1990; Shields, 1991; Vanolo, 2008). However, it is argued that the external images are frequently regarded as vague, abstract, and simplistic (Entrikin, 1990; Shields, 1991; Vanolo, 2008). Conversely, these images are essential as they enable the urban planners and city development authorities to organize information, formulate generalizations and expectations, and guide further actions like the choices made by tourists and investors (Entrikin, 1990; Shields, 1991; Vanolo, 2008). More importantly, these considerations have given rise to interests and efforts of many cities in branding (i.e., building positive and charming images) (Kavaratzis \& Ashworth, 2005), which could act as an important tool to attract flows of tourism and investments, to name a few, and to promote local development (Gold \& Ward, 1994; Vanolo, 2008).

According to Gertler (2004), many cities in the postindustrial era attempted to make places attractive to a target audience, for example, to the artistic communities, who have a preference for vibrant artistic networks, who seek a climate that offers support to their arts and offers a good and affordable quality of life. Creative image of cities is an outcome of such processes depending on the activities they perform and attributes they possess (Shields, 1991; Vanolo, 2008). For example, New York is known as the financial capital of the world; more recently Dubai is acknowledged as the world's top immigration hub (Benton-Short, Price, \& Friedman, 2005) as its rulers sought to make this condition a brand of the MiddleEastern metropolis (Acuto, 2010); Osaka is known as the intelligent city; Amsterdam caught the attention for its ports and capacity to conduct world trade; Florence captivated people through its painting, sculpture, crafts and even the technology of the era (Hall, 1998; Savitch, 2010); and most recently Putrajaya in Malaysia reflects the changing national priorities and understandings of national identity (Goh \& Liauw, 2009; Moser, 2010).

Towards the end of the last millennium and start of this millennium, classical works of Florida (2002, 2003, 2005), Landry (2006), and Landry and Bianchini (1995) emphasized the idea of the 'creative city'. Later on, with the passing of time, creativity has become an important buzz word in urban planning and more importantly in urban-marketing policies across the world. In its simplest form it is argued that capitalist development has moved to a new distinct phase, where the driving force of the economy is no more technological or organizational, but human (Peck, 2005; Vanolo, 2008). According to Peck (2005), in such a framework a key question for urban planning refers to the possibility of promoting creative environments and 'cool city' images. Central to this framework remains the availability and presence of creative professionals, and formation of an attractive and inviting environment for these professionals, which include knowledge workers, researchers, in- 
novators, artists, and so on. For example, ICT professionals and knowledge workers who remain as the backbone of ICT activities that influence economy and society through business, productivity, social contacts, education and creativity, to name a few, have distinct aspirations, needs and ways of life. They also act as a driving force to transform the society, enable socioeconomic growth of a city and also engender a creative city image (Van der Vyver \& Marais, 2015; Castells, 2000; Das \& Emuze, 2014; Andoh-Baidoo, Osatuyi, \& Kunene, 2014; Ponelis \& Holmner, 2015; Rantanen, 2001; Yang \& Meng, 2001). Thus, the availability of ICT professionals and knowledge workers in cities offers distinct images to the cities. Therefore, it is argued that creative professionals possess unique characteristics and their motivations are different from normal people of the cities. They are the actual producers of new values that reshape the world, and place their cities at the cutting edge of change (Friedmann, 1986; Sassen, 1991). Such creative professionals are not merely motivated by material rewards of economic and financial benefits but seek to live in quality, creative, tolerant and exciting places (Peck, 2005; Vanolo, 2008). Scholars like Florida (2002, 2005), affirmed that this creative class is attracted by such places, thus development of such places fit within the theoretical framework of building cities based on external and internal images.

Florida $(2002,2005)$ argued that creative city policies should aim at the construction of desirable environments for the creative class and the display of the creative image of the city; although such policies may be elitist selective policies, which include speculative real estate development, gentrification, enhancement of specific neighbourhoods, and construction of landmarks designed by famous architectural stars (Peck, 2005). On the contrary, Sandercock (2003) argued that creative in terms of promotional policies and urban branding means a set of practices of selective story telling aimed at creating an intended understanding and impression on the potential visitors, investors or even inhabitants (Vanolo, 2008). Thus, the issues emerge that engendering creativity, development of a creative city image and city branding have become part of the city development process. Creativity is related to economic development, attracting investment (FDI), enhancing tourism and attracting skilled and creative workforce to a city. Many cities across the world and in developing countries like India and South Africa keep the aspirations to transform their cities and build a creative image, which is evidenced from their policy and programmes (IDP, Mangaung, 2015; City Development plan, Bhubaneswar, 2006). However, efforts to develop such images and branding are being made based on the core theoretical arguments of creative city approach, although these theoretical approaches have often been criticized as elitism, ambiguous and being based on incongruent data (Peck, 2005; Scott, 2000, 2006; Vanolo, 2008). Besides, despite the incorporation of the influence of ICT and consequent rapid change in urban activities in cities, approaches by considering ICT as a core element in creative city image creation and branding are scarce. Therefore, although creative image implies the creation and representation of environments perceived as suitable for creative industries, both by city users and external actors (Vanolo, 2008), there is yet a necessity to explore how ICT should act as a catalyst to engender a creative city image in developing countries.

\section{Results and Discussion}

The images of creative cities were evaluated by considering the various influential economic, socio-cultural, environmental and technological variables that prompt a creative image of a city. Consequently, the evaluation was conducted under two aspects such as (1) the influence of economic, socio-cultural, environmental and technological attributes of the city in engendering a creative city image, and (2) the influence of ICT in reinforcing the economic, socio-cultural and environmental attributes to induce a creative city image. The analysis of a creative city image scenario was done based on the measured perception indices (PI); significance tests ( $p$ values based on t-tests) between the perception indices of various economic, socio-cultural, environmental and technological variables and perception indices obtained from evaluation of responses received from the survey on the overall image of the two case study cities considered in the study. The analysis of both cities was first done separately and then in combination to obtain an overall picture.

\subsection{Influence of Economic, Socio-Cultural, Environmental and Technological Variables on Creating an Image of Cities}

Table 2 presents the level of influence of socio-economic, environmental and technological variables in developing an image of a creative city for both Bhubaneswar and Bloemfontein separately and then in combination. The high Cronbach $\alpha$ values (ranging between 0.84 and 0.89) of the different variables indicate that the data is reliable and can be used for further analysis. The low SD values (ranging between 0.12 and 0.23 ) indicate the consistency in the responses, so eliminating the prejudices and biases. A perception index higher than 0.6 is also considered as the threshold value for enforcing a positive creative city image based on the opinions of the stakeholders ${ }^{1}$.

Under economic attributes it is found that in Bhubaneswar city, business environment, availability of knowledge based activities, and availability of knowledge based workers (with $\mathrm{PI}>0.6$ and $\mathrm{p}$-values for both one-tailed and two-tailed $<0.05$ for $\alpha<0.05$ ) create a positive image of a creative city. However, lower PI values

\footnotetext{
${ }^{1}$ Based on the perception of urban development professionals, experts and decision makers.
} 
Table 2. Level of influence of socio-economic, environmental and technological variables in developing an image of creative cities.

\begin{tabular}{|c|c|c|c|c|c|c|}
\hline \multirow[t]{2}{*}{ Attributes } & \multicolumn{2}{|c|}{ Bhubaneswar } & \multicolumn{2}{|c|}{ Bloemfontein } & \multicolumn{2}{|r|}{ Overall } \\
\hline & $\%$ & $\begin{array}{l}\text { Perception } \\
\text { index (PI) }\end{array}$ & $\%$ & $\begin{array}{l}\text { Perception } \\
\text { index (PI) }\end{array}$ & $\%$ & $\begin{array}{l}\text { Perception } \\
\text { index (PI) }\end{array}$ \\
\hline \multicolumn{7}{|l|}{ Economic attributes } \\
\hline Business environment & 59.3 & $0.62 *$ & 47.6 & $0.49 * *$ & 54.8 & $0.57^{* *}$ \\
\hline Entrepreneurship & 57.8 & $0.59 * *$ & 45.8 & $0.48 * *$ & 53.2 & $0.55^{* *}$ \\
\hline Innovation & 37.6 & $0.33^{* *}$ & 46.6 & $0.48 * *$ & 41.0 & $0.39 * *$ \\
\hline e-Commerce & 43.2 & $0.45^{* *}$ & 41.6 & $0.44 * *$ & 42.6 & $0.45^{* *}$ \\
\hline Availability of knowledge based activities & 72.4 & $0.76^{*}$ & 54.3 & $0.56 * *$ & 65.5 & $0.68 *$ \\
\hline Availability of knowledge based workers & 68.4 & $0.72 *$ & $52.7^{*}$ & $0.54 * *$ & 62.4 & $0.65^{*}$ \\
\hline Activities relating to arts & 62.5 & $0.66^{*}$ & 57.4 & $0.60 *$ & 60.6 & $0.64 *$ \\
\hline Cultural activities & 75.8 & $0.79 *$ & 61.2 & $0.64 *$ & 70.2 & $0.73^{*}$ \\
\hline Availability of architectural elements & 84.7 & $0.88^{*}$ & 55.6 & $0.57 * *$ & 73.6 & $0.76^{*}$ \\
\hline
\end{tabular}

\section{Socio-cultural attributes}

Inclination of people towards building and

architectural elements

Creation of symbolic elements

$\begin{array}{llllll}67.6 & 0.69^{*} & 74.2 & 0.76^{*} & 70.1 & 0.72^{*} \\ 72.7 & 0.74^{*} & 72.9 & 0.75^{*} & 72.8 & 0.74^{*} \\ 67.4 & 0.71^{*} & 66.8 & 0.69^{*} & 67.2 & 0.70^{*} \\ 69.8 & 0.73^{*} & 65.7 & 0.67^{*} & 68.2 & 0.71^{*} \\ 71.6 & 0.74^{*} & 56.3 & 0.59^{* *} & 67.6 & 0.70^{*}\end{array}$

Receptive attitude

Tolerance

Safety

$71.60 .74 *$

$67.6-0.70^{*}$

\section{Environmental attributes}

Clean environment

Availability of greenery

Level of tourism activities

Availability of quality public spaces

Availability of spatial hotspots

58.3

$58.3 \quad 0.62 *$

$54.70 .57 * *$

$84.80 .87^{*}$

$62.50 .65^{*}$

$56.30 .58^{* *}$

75.2
68.9
36.6
60.4
57.6

$0.79^{*}$
$0.71^{*}$
$0.39 * *$
$0.61 *$
$0.59 * *$

$\begin{array}{ll}64.8 & 0.69^{*} \\ 60.1 & 0.62^{*} \\ 66.4 & 0.69^{*} \\ 61.7 & 0.63^{*} \\ 56.8 & 0.58^{* *}\end{array}$

Technological attributes

Availability of ICT facilities

Penetration of ICT in urban activities

Quality of ICT facilities

$\begin{array}{ll}68.7 & 0.69 * \\ 62.6 & 0.64^{*} \\ 48.6 & 0.50^{* *} \\ 45.5 & 0.47^{* *}\end{array}$

76.9

75.8

$0.79 *$

$0.78 *$

$65.80 .68^{*}$

$72.7 \quad 0.74 *$

$\begin{array}{ll}71.8 & 0.73 * \\ 67.6 & 0.69 * \\ 55.2 & 0.57 * * \\ 55.9 & 0.57 * *\end{array}$

Level of use of ICT facilities in urban activities

$0.74^{*}$

$55.90 .57^{* *}$

Notes: Cronbach $\alpha$ range: (0.84 to 0.89 ), SD range of PI: (0.12 to 0.23 ); ${ }^{*} \mathrm{p}$ (one-tailed and two-tailed) $<0.05$ for $\alpha<0.05$, statistically significant; ${ }^{* *} p$ (one-tailed and two-tailed) $>0.05$ for $\alpha<0.05$, statistically insignificant.

of innovation, entrepreneurship and e-commerce do not portray such an image, which is corroborated by the significance test results ( $p$-values for both one-tailed and two-tailed $>0.05$ for $\alpha<0.05$ ) (Table 2). In Bloemfontein, none of the variables under economic attributes indicate that they foster any positive image of a creative city $(\mathrm{PI}$ values for all variables $<0.6$ and $\mathrm{p}$-values $>0.05$ for $\alpha<0.05)$. Moreover, in the current state, the overall status of business environment, entrepreneurship, ecommerce and innovation are barriers against developing a creative city image (Table 2).

In Bhubaneswar, all the socio-cultural variables such as activities relating to arts, cultural activities, availability of architectural elements, inclination of people towards building and conserving architectural elements, creation of symbolic elements, receptive attitude, tolerance and safety have higher perception indices ( $\mathrm{PI}$ values $>0.6$ ). Be- sides, the relationship between the creative image indices and PI of these variables is statistically significant ( $p$-values for both one-tailed and two-tailed $<0.05$ for $\alpha<0.05)$. However, in Bloemfontein all the socio-cultural variables other than safety and availability of architectural elements convey a creative city image (PI values $>0.6$; $p$-values for both one-tailed and two-tailed $<0.05$ for $\alpha<0.05)$. Perceptions of poor safety and lack of architectural elements in the city do not symbolise the city as a creative city $(\mathrm{PI}<0.6 ; \mathrm{p}$-values for both one-tailed and two-tailed $>0.05$ for $\alpha<0.05$ ). Overall, the socio-cultural attributes promote an image of a creative city.

Environmental attributes show mixed indications in both the cities. Lack of availability of adequate greenery and lack of spatial hotspots in Bhubaneswar, and lack of significant tourism activities and lack of availability of spatial hotspots in Bloemfontein $(\mathrm{PI}$ values $<0.6$, 
supported by $p$-values $>0.05$ for $\alpha<0.05$ ) act as challenges in fostering an image of creative cities. However, tourism activities, clean environment, and quality of public spaces in Bhubaneswar engender a creative city image. Similarly, clean environment, availability of greenery and quality of public space are the most notable variables which prompt the creative city image in Bloemfontein.

Under the technological attributes, all the four variables such as availability of ICT facilities, penetration of ICT in urban activities, quality of ICT facilities and level of use of ICT facilities in urban activities (PI values $>0.6$, $p$ values for both one tailed and two tailed $<0.05$ for $\alpha<0.05)$ are found to posit a creative city image in Bloemfontein. In Bhubaneswar in contrast the quality of ICT facilities and level of use of ICT facilities in urban activities $(\mathrm{PI}<0.6, \mathrm{p}$ values $>0.05$ for $\alpha<0.05)$ act as barriers against building a creative city image in the city.

As both the cities are similar in characteristics and have similar aspirations, it is found that overall the availability of knowledge based activities, and knowledge based workers under economic attributes; all the socio-cultural attributes; clean environment, availability of greenery, level of tourism activities and availability of quality public spaces under environmental attributes; and availability of ICT facilities and penetration of ICT in urban activities create an image of a creative city. However, challenges remain in other variables with respect to business environment, entrepreneurship, innovation, e-commerce, availability of spatial hotspots, quality of ICT and level of use of ICT facilities in urban activities. Thus, as evident from this analysis, both cities have significant potential to create an image of a creative city respectively despite a few challenges.

\subsection{Influence of ICT on Creative Image of Cities}

As both cities have significant potential to develop the image of a creative city, and in recent years ICT has become an influential factor in every urban activity, it was essential to explore how ICT is engendering a creative city image in both the cities. Before evaluating the influence of ICT on a creative city image, data was checked for consistency and reliability. The high Cronbach $\alpha$ values (ranging between 0.84 and 0.89 ) and low SD (ranging between 0.11 and 0.24 ) of different variables indicate that the data is reliable and consistent and can be used for further analysis. Table 3 presents the level of influence of ICT on the different economic, socio-cultural and environmental attributes, which enable a creative city image. The evaluation was made by considering to what extent ICT is enhancing or enabling or reinforcing the various attributes in the cities. The results revealed that ICT reinforces economic attributes such as knowledge based activities and assists in attracting knowledge based workers to both the cities. Additionally it enables a better business environment in Bloemfontein (PI values $>0.6$; $p$ - values one-tailed and two-tailed $<0.05$ for $\alpha<0.05)$. On the other hand ICT does not have much influence on enhancing entrepreneurship, encouraging innovation and enhancing e-commerce $(\mathrm{PI}<0.6 ; \mathrm{p}$-values one-tailed and two-tailed $>0.05$ for $\alpha<0.05$ ) in both cities.

Besides, ICT is found to augment activities relating to arts, boost cultural activities, stimulate creation of symbolic elements, develop receptive attitude, imbibe tolerance, and enhance social cohesion ( $\mathrm{PI}$ values $>0.6$; $p$-values one-tailed and two-tailed $<0.05$ for $\alpha<0.05$ ) in both cities. However, it does not have much influence in promoting architectural elements, encouraging people towards building and conserving architectural elements and improving safety in both cities as seen from the PI values and significance tests $(\mathrm{PI}<0.6$; $\mathrm{p}$ one-tailed and twotailed $>0.05$ for $\alpha<0.05$ ).

Environmentally, ICT assists in encouraging tourism activities, promoting public spaces and creating spatial hotspots in both the cities (PI values >0.6; $p$-values onetailed and two-tailed $<0.05$ for $\alpha<0.05)$. Additionally, ICT also fosters greenery and clean environment in Bloemfontein. A discussion with stakeholders such as municipal officials, councillors and ICT professionals corroborated this finding as information transferred through ICT regarding environmental protection, assists in creating cleanliness and engendering greenery ${ }^{2}$. Contrary to this, ICT does not promote a clean environment and greenery in Bhubaneswar as people remain unmindful of the promotional activities related to environmental protection ${ }^{3}$.

A close examination of the influence of ICT on various attributes show that ICT has a similar influence in both cities but for a few exceptions. The performance of the majority of attributes indicates that ICT is pivotal in developing a creative city image in both cities. As seen from the overall evaluations, ICT enables a better business environment, reinforces knowledge based activities, and attracts knowledge based workers under economic attributes. It promotes almost all socio-cultural attributes except promoting architectural elements, offering encouragement to people for building and conserving architectural elements and improving safety. It also assists in engendering a clean environment, encouraging tourism activities, promoting public spaces and creating spatial hotspots, although fostering greenery remains as a challenge. Thus, it is evident that ICT has significant influence on drawing a creative city image. However, it is also evident that despite the similarities between the two cities with regards to their attributes in creating a creative city image, the presence of certain distinctive attributes and the varied level of influence of ICT on these attributes prompt for unique images of the cities based on the policies and paths they follow. For example, whereas ICT influences extensively in enabling business environment and promoting greenery and cleanliness in Bloemfontein, it attracts knowledge workers to- and promotes tourism significantly in Bhubaneswar.

\footnotetext{
2 Opinion of common people and municipal officials.

${ }^{3}$ Opinion of municipal officials and councillors.
} 
Table 3. Level of influence ICT in developing a creative image.

\begin{tabular}{|c|c|c|c|c|c|c|}
\hline \multirow[t]{2}{*}{ Attributes } & \multicolumn{2}{|c|}{ Bhubaneswar } & \multicolumn{2}{|c|}{ Bloemfontein } & \multicolumn{2}{|r|}{ Overall } \\
\hline & $\%$ & $\begin{array}{l}\text { Perception } \\
\text { index (PI) }\end{array}$ & $\%$ & $\begin{array}{l}\text { Perception } \\
\text { index (PI) }\end{array}$ & $\%$ & $\begin{array}{l}\text { Perception } \\
\text { index (PI) }\end{array}$ \\
\hline \multicolumn{7}{|l|}{ Economic attributes } \\
\hline Enabling better business environment & 55.3 & $0.58 * *$ & 72.7 & $0.76^{*}$ & 62.0 & $0.65^{*}$ \\
\hline Enhancing entrepreneurship & 54.2 & $0.56 * *$ & 55.7 & $0.58^{*}$ & 54.8 & $0.57^{* *}$ \\
\hline Encouraging innovation & 42.6 & $0.46^{* *}$ & 56.4 & $0.58 * *$ & 47.9 & $0.51 * *$ \\
\hline Enhancing e-commerce & 56.8 & $0.59 * *$ & 54.9 & $0.57^{* *}$ & 56.1 & $0.58 * *$ \\
\hline Reinforcing knowledge based activities & 87.4 & $092 *$ & 86.3 & $0.88^{*}$ & 87.0 & $0.90 *$ \\
\hline Attracting knowledge based workers & 78.4 & $0.82 *$ & $68.2^{*}$ & $0.72 *$ & 74.5 & $0.78^{*}$ \\
\hline \multicolumn{7}{|l|}{ Socio-cultural attributes } \\
\hline Augmenting activities relating to arts & 68.5 & $0.69 *$ & 71.3 & $0.75^{*}$ & 69.6 & $0.71 *$ \\
\hline Boosting cultural activities & 65.7 & $0.67 *$ & 68.3 & $0.71^{*}$ & 66.7 & $0.69 *$ \\
\hline Promoting architectural elements & 44.9 & $0.48 * *$ & 39.4 & $0.43^{* *}$ & 42.8 & $0.46 * *$ \\
\hline Encouraging people towards building and & & & & & & \\
\hline conserving architectural elements & 48.3 & $0.53 * *$ & 47.9 & $0.51^{* *}$ & 48.1 & $0.52 * *$ \\
\hline Stimulating creation of symbolic elements & 67.4 & $0.72 *$ & 65.9 & $0.68^{*}$ & 66.8 & $0.70^{*}$ \\
\hline Developing receptive attitude & 62.3 & $0.64^{*}$ & 64.7 & $0.67^{*}$ & 63.2 & $0.65^{*}$ \\
\hline Imbibing tolerance & 65.8 & $0.70^{*}$ & 68.2 & $0.71^{*}$ & 66.7 & $0.70^{*}$ \\
\hline Enhancing social cohesion & 73.2 & $0.77^{*}$ & 63.4 & $0.66^{*}$ & 69.5 & $0.73^{*}$ \\
\hline Improving safety & 57.4 & $0.59 * *$ & 54.6 & $0.56 * *$ & 56.3 & $0.58 * *$ \\
\hline \multicolumn{7}{|l|}{ Environmental attributes } \\
\hline Engendering clean environment & 55.4 & $0.58 * *$ & 59.8 & $0.63 *$ & 57.3 & $0.60 *$ \\
\hline Fostering greenery & 52.3 & $0.54 * *$ & 58.9 & $0.62^{*}$ & 54.8 & $0.57 * *$ \\
\hline Encouraging tourism activities & 77.4 & $0.79 *$ & 56.7 & $0.60 *$ & 69.5 & $0.72 *$ \\
\hline Promoting public spaces & 64.3 & $0.68^{*}$ & 66.3 & $0.69 *$ & 65.1 & $0.68^{*}$ \\
\hline Creating spatial hotspots & 68.4 & $0.72 *$ & 63.4 & $0.66^{*}$ & 66.5 & $0.70 *$ \\
\hline
\end{tabular}

Notes: Cronbach $\alpha$ range: (0.84 to 0.89$)$; SD range of PI: (0.11 to 0.24$) ;{ }^{*} \mathrm{p}$ (one tailed and two tailed) $<0.05$ for $\alpha<0.05$, statistically significant; ${ }^{* *} \mathrm{p}$ (one tailed and two tailed) $>0.05$ for $\alpha<0.05$, statistically insignificant.

\subsection{Discussions}

Technology has become a symbol of power and competitiveness with enormous socio-economic and environmental consequences (Acuto, 2010; Callon, 1986). Technology-particularly ICT-has been able to control the economic development, social articulation and environmental consequences and created either positive or negative dynamics among the various attributes. The interaction of ICT and all these attributes coexist in a plurality of competing, complementary and overlapping, symbolic and spatial orders that define the socio-economic and environmental texture of cities (Acuto, 2010; King, 2004, p. 3). Creative city image is an offspring of these interactions. The integration of ICT in every sphere of cities, which is envisaged to dictate the spatial organization as well as the socio-economic functions and practices, can engender an explicit image (Acuto, 2010; Florida, 2002, 2003, 2005; Sassen, 1999). As seen from the evaluations of the attributes of both the cities and the influence of ICT, it is emanated that ICT has a significant presence and is largely influencing every sphere of city life tending to create a distinctive image in both the cities. The findings of the two case studies suggest that ICT has become an enabler for enhanced knowledge based activities, and to attract knowledge based workers under economic attributes. According to certain stakeholders such as businessmen and people engaged in ICT industry activities as evidenced from this study, knowledge based activities and knowledge based professionals have significant presence in both cities and ICT has been able to reinforce these activities as well attract knowledge based workers-particularly to Bhubaneswar, although to a relatively lesser extent to Bloemfontein-and ICT also enables a better business environment, particularly in Bloemfontein ${ }^{4}$. This study also suggests that ICT enhances the majority of socio-cultural attributes like arts, culture, tolerance, social cohesion, safety and symbolic creation. It also enhances tourism activities, promotes public places and assists in creation of spatial hotspots in both cities ${ }^{5}$, which can promote a creative environment and create exciting places corroborating the findings of

\footnotetext{
${ }^{4}$ Opinions of businessmen and ICT professionals.

${ }^{5}$ Opinions of majority of stakeholders.
} 
scholars like Florida (2002, 2003, 2005), Peck (2005) and Sandercock (2003). However, ICT also influences differently on different elements, based on context, type and functions of the cities as evidenced from the two cities. For example, ICT acted as an enabler of the creation of a congenial business environment in Bloemfontein although the same can not be true for Bhubaneswar. Similarly, while ICT engenders a clean environment and greenery in Bloemfontein, it does not suffice to creation of such elements in Bhubaneswar. Consequently, it suffices to argue that both the cities have the potential to develop as creative cities and develop their own stories which they can tell through their promotion and branding, based on the creative city image they pursue to craft, and it is envisaged that ICT can play a catalytic role in engendering a creative city image in developing countries.

\section{Conclusion}

Creative city has become a buzz word in many parts of the world. The creation of an image and promotion and branding of cities to attract investment, tourists, skilled professionals, knowledge based workers and creative people to cities have become a key objective of decision makers of many cities in the world. Not only the large and world renowned cities, but also relatively smaller cities in the developing world-like in India and South Africa have nurtured the aspiration to develop their cities to exciting places and to create an explicit image to make them attractive. Although Florida's work (2002, 2003, 2005) opened a debate on creative city image, it is observed that not much headway has been made in this field as evidenced from the literature so far. Besides, many scholars have criticised the concept as being non-realistic, elitist and ambiguous. Despite these pitfalls more and more cities are inclined towards developing a creative city image and using technology as a symbol of power and image. ICT in recent years has entered every sphere of city life and is found to be influencing every urban activity. Thus, it is imperative that ICT is expected to play a pivotal role in the image building of cities in the future. Since not much study has been devoted to this particular aspect, this study attempted to comprehend how ICT can engender a creative city image in the cities of developing countries. Looking at the aspirations of the two case study cities-Bhubaneswar and Bloemfontein-to transform into world class and smart cities, such a study was considered imperative. A survey research methodology was pursued to realise the aim of the study. The findings suggest that both the cities have the potential to engender creative city images respectively. ICT is found to be significantly influential to create this image. Overall, ICT enables a better business environment, reinforces knowledge based activities, attracts knowledge based workers under economic attributes and promotes almost all socio-cultural attributes except promoting architectural elements, encouraging people towards building and conserving architectural elements and improving safety. ICT also assists in engendering a clean environment, encouraging tourism activities, promoting public spaces and creating spatial hotspots. Thus, it is evident that ICT has a significant influence on drawing up a creative city image.

The investigation has certain limitations as it is based on primary survey data in all attributes in the absence of structured statistical data, which would have provided critical insights in the issues - particularly with regard to economic attributes. Nevertheless, at its current state, it is construed that ICT can significantly engender and reinforce an image of a creative city.

\section{Acknowledgments}

The author appreciates the assistance and support of his colleagues and of people who have helped him with the data collection process. The author thanks all the respondents for their support. The author also thanks the two anonymous reviewers for their positive and insightful comments to improve the paper.

\section{Conflict of Interests}

The author declares no conflict of interests.

\section{References}

Acuto, M. (2010). High-rise Dubai urban entrepreneurialism and the technology of symbolic power. Cities, 27, 272-284.

Andoh-Baidoo, F. K., Osatuyi, B., \& Kunene, K. N. (2014). ICT capacity as the investment and use of ICT: Exploring its antecedents in Africa. Information Technology for Development, 20(1), 44-59. doi:10.1080/ 02681102.2013 .804399

Batty, M. (1971). Modelling cities as dynamic systems. Nature, 231, 425-428.

Batty, M. (2012). Building a science of cities. Cities, 29, S9-S16.

Benton-Short, L., Price, M., \& Friedman, S. (2005). Globalization from below: The ranking of global immigrant cities. International Journal of Urban and Regional Research, 29(4), 945-959.

Callon, M. (1986). Some elements of sociology of translation. In P. Hall (Ed.), Power, action and belief: $A$ new sociology of knowledge. London: Weidenfeld \& Nicolson.

Castells, M. (2000). The rise of the network society: The Information Age: Economy, society, and culture volume I. Oxford: Wiley-Blackwell.

City Development Plan, Bhubaneswar (2006). City Development Plan, Bhubaneswar, Final Report, IndoUSAID financial institutions reform and expansion project, Debt and Infrastructure component, (FIRE-D Project, USAID-TCGI contract no:386-C-00-04-0011900). Washington, DC: USAID.

Das, D., \& Emuze, F. (2014). Smart city perspectives of Bloemfontein. Journal of Construction Project Man- 
agement and Innovation, 4(2), 930-950.

Entrikin, N. (1990). The betweenness of place: Towards a geography of modernity. Basingstoke: Macmillan.

Florida, R. (2002). The rise of the creative class and how it's transforming work, leisure, community, and everyday life. New York: Basic Books.

Florida, R. (2003). Cities and the creative class. City \& Community, 2(1), 3-19.

Florida, R. (2005). Cities and the Creative Class. London: Routledge.

Friedmann, J. (1986). The world city hypothesis. Development and Change, 17, 69-83.

Gertler, M. S. (2004). Creative cities: What are they for, how do they work, and how do we build them?. Ottawa: Canadian Policy Research Networks.

Goh, B. L., \& Liauw, D. (2009). Post-colonial projects of a national culture. City: Analysis of Urban Trends. Culture, Theory, Policy, Action, 13(1), 71-79.

Gold, J. R., \& Ward, S. V. (1994). Introduction. In place promotion. In S. V. Ward \& J. R. Gold (Eds.), The use of publicity and marketing to sell towns and regions, (pp. 1-17). Chichester: John Wiley \& Sons.

Giffinger, R., Fertner, C., Kramar, H., Kalasek, R., PichlerMilanović, N., \& Meijers, E. (2007). Smart citiesranking of European medium-sized cities. Final report. Vienna: Centre of Regional Science, Vienna UT.

Hall, P. (1998). Cities in Civilization. New York: Random House.

IDP. (2015). Integrated development plan. Mangaung Metro Municipality, South Africa.

Jessop, B., \& Sum, N. L. (2000). An entrepreneurial city in action: Hong Kong's emerging strategies in and for (inter) urban competition. Urban Studies, 31(12), 22872313.

Jiang, Y., \& Shen J. (2010). Measuring the urban competitiveness of Chinese cities in 2000. Cities, 27, 307-314.

Kavaratzis, M. \& Ashworth, G. J. (2005). City branding: An effective assertion of identity or a transitory marketing trick?. Tijdschrift Voor Economischeen Sociale Geografie, 96(5), 506-514.

King, A. (2004). Worlds in the city: From wonders of modern design to weapons of mass destruction. In A. King (Ed.), Spaces of Global Cultures: Architecture, Urbanism, Identity. London: Routledge.

Lalli, M. (1992). Urban related identity: Theory, measurement and empirical findings. Journal of Environmental Psychology, 12, 285-303.

Lambsdorff, J. G. (2006). The Methodology of the corruptions perceptions index. Passau: Transparency International and the University of Passau. Retrieved from http://www.icgg.org/downloads/CPI_ 2006_Methodology.pdf

Landry, C. (2006). The Art of City Making. London: Earthscan.

Landry, C., \& Bianchini, F. (1995). The Creative City. London: Demos.

Lever, W. F. (1993). Competition with the European urban system. Urban Studies, 30(6), 935-948.
Miller, J. H., \& Page, S. E. (2007). Complex adaptive systems: An introduction to computational models of social life. Princeton, NJ: Princeton University Press.

Moser, S. (2010). Putrajaya: Malaysia's new federal administrative capital, Cities, 27, 285-297.

Nardo, M., Saisana, M., Saltelli, A., Tarantola, S., Hoffman, A., \& Giovannini, E. (2005). Handbook on constructing composite indicators: Methodology and users guide (OECD Statistics Working Paper, STD/DOC (2005) 3, JT00188147). Paris: OECD.

Peck, J. (2005). Struggling with the creative class. International Journal of Urban and Regional Research, 29(4), 740-770.

Ponelis, S. R., \& Holmner, M. A. (2015). ICT in Africa: Building a better life for all. Information Technology for Development, 21(2), 163-177. doi:10.1080/ 02681102.2015 .1010307

Rantanen, T. (2001). The old and the new: Communication technology and globalization in Russia. New Media and Society, 3, 85-105. doi:10.1177/ 1461444801003001006

Saltelli, A. (2007). Composite indicators between analysis and advocacy. Social Indicators Research, 81, 65-77.

Sandercock, L. (2003). Cosmopolis II. Mongrel cities for the 21st century. London: Continuum.

Sassen, S. (1991). The global city. Princeton: Princeton University Press.

Sassen, S. (1999). Guests and aliens. New York: New Press.

Savitch, H. V. (2010). What makes a great city great? An American perspective. Cities, 27, 42-49.

Scott, A. J. (2000). The cultural economy of cities. London: Sage.

Scott, A. J. (2006). Creative cities: Conceptual issues and policy questions. Journal of Urban Affairs, 28(1), 1-17.

Shen, J. (2004). Urban competitiveness and urban governance in the globalizing world. Asian Geographer, 23(1/2), 19-36.

Shen, J. (2007). Scale, state and the city: Urban transformation in post reform China. Habitat International, 31(3/4), 303-316.

Shen, J. (2008). Hong Kong under Chinese sovereignty: Economic relations with mainland China, 1978-2007. Eurasian Geography and Economics, 49(3), 326-340.

Shields, R. (1991). Places on the margin. Alternative geographies of modernity. London: Routledge.

Van der Vyver, A. G., \& Marais, M. (2015). Evaluating users' perceptions of the Digital Doorway: A narrative analysis. Information Technology for Development, 21(1), 99-112. doi:10.1080/02681102.2013.841629

Vanolo, A. (2008). The image of the creative city: Some reflections on urban branding in Turin. Cities, 25, 370382. doi:10.1016/j.cities.2008.08.001

Xu, J., \& Yeh, A. G. O. (2005). City repositioning and competitiveness building in regional development: New development strategies in Guangzhou, China. International Journal of Urban and Regional Research, 
29(2), 283-308.

Yang, H., \& Meng, Q. (2001). Modeling user adoption of advanced traveler information systems: Dynamic evolution and stationary equilibrium. Transportation Research Part A, 35(10), 895-912.

\section{About the Author}

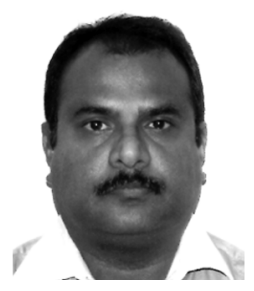

Dillip Kumar Das is a PhD in Urban and Regional planning. Currently he is engaged in teaching, research and community engagement activities in the Department of Civil Engineering of Central University of Technology, Free State, South Africa. He has taught and guided both undergraduate and post graduate students of Civil Engineering, Architecture and Urban Planning. His research and consulting interests include systems analysis, infrastructure planning, green cities, smart cities, transportation planning, and tourism development. He has also supervised doctoral students under Southern African Young Scientist Summer Programme (SA YSSP) 2013-15 and currently working as a supervisor for PhD scholars for the Southern African Systems Analysis Centre (SASAC). 